\title{
PREVALENCE OF DIABETIC RETINOPATHY IN TYPE-2 DIABETES MELLITUS PATIENTS IN TRIPURA
}

Arindam Dattaํㅜㄹ Amar Kanti Chakma², Debasis Datta ${ }^{3}$

\section{HOW TO CITE THIS ARTICLE:}

Arindam Datta, Amar Kanti Chakma, Debasis Datta."Prevalence of Diabetic Retinopathy in Type-2 Diabetes Mellitus patients in Tripura".Journal of Evolution of Medical and Dental Sciences 2014; Vol. 3, Issue 01, January 06; Page: 136-146.

ABSTRACT: OBJECTIVE: To study the prevalence of diabetic retinopathy and its relationship with the various risks factors in type 2 diabetes mellitus patients. PATIENTS AND METHODS: One hundred type 2 diabetes mellitus patients attending the departments of Medicine and Ophthalmology of TMC \&Dr. BRAM Teaching Hospital comprised the material of this study. Detailed history, clinical examination and thorough ophthalmological examination including fundus photography of all the diabetic patients under study were done. The glycaemic control was evaluated for all the subjects by estimation of blood glucose and HbA1c, presence of microalbuminuria and lipid profiles. RESULTS: There were 61 (61\%) females and 39 (39\%) males in the study of which 42 (42\%) patients, 15(35.7\%) males and 27(64.3\%) females had diabetic retinopathy. Among 42 retinopathy patients NPDR, PDR and ADR were 15(35.7\%), 17 (40.48\%) and $10(23.81 \%)$ respectively. Duration of diabetes was found the most significant contributory factor in the causation of DR (Chi-square - 43.66; p<0.01\& F- 78.037, p=0.00). Other factors which were significantly associated with diabetic retinopathy are age $(\mathrm{p}=0.00)$, glycaemic control as assessed by HbA1c $(\mathrm{p}=0.00)$, blood glucose- fasting $(\mathrm{p}=0.00) \&$ postprandial $(\mathrm{p}=0.00)$ and MAU $(\mathrm{p}=0.00)$. Factors like blood pressure- Systolic $(p=0.655)$ \& diastolic $(p=0.964)$, hypercholesterolemia $(\mathrm{p}=0.140)$, and BMI ( $\mathrm{p}=0.513)$ did not show any significant correlation.

KEY WORDS: Diabetic retinopathy, type 2 diabetes mellitus

INTRODUCTION: Diabetic retinopathy (DR) is a sight threatening, chronic microvascular complication of diabetes mellitus that eventually afflicts most patients with DM despite the availability of various modalities of treatment. Upto two percent of type-2 diabetes have retinopathy at the time of first diagnosis and more than $60 \%$ of them have some degree of retinopathy by twenty years of diagnosis. ${ }^{1}$

DR is a major global cause of total blindness according to the global update of available data on visual impairment in the year 2002. ${ }^{2}$ Its prevalence was estimated to be as high as $4.8 \%$ of the total of blindness. It is the leading cause of new-onset blindness among American adults aged 20-74 years $^{3}$ with an estimated 24,000 people losing vision each year as a consequence. The risk factors identified to be related to the progression of DR are duration of DM, glycemic control, blood pressure and microalbuminuria. Data on other factors including BMI, male sex, serum lipids and smoking have demonstrated varying results. ${ }^{4}$ We aim to study the prevalence of DR in Tripura and its correlation with age, obesity, glycemic control, hypertension and dyslipidemia as there is no data regarding the DR in Tripura so far.

PATIENTS AND METHODS: This study was carried out in Tripura Medical College and Dr. BRAM Teaching Hospital in the departments of Medicine and Ophthalmology for a period of one year with 


\section{ORIGINAL ARTICLE}

effect from $1^{\text {st }}$ June 2010 to $31^{\text {st }}$ May 2011. One hundred patients of type 2 diabetes patients were selected randomly for this study. Patients with chronic renal failure, chronic liver disease, COPD, carcinoma, critical illness (sepsis, hyperosmolar coma) were excluded from the study. The diagnosis of type 2 diabetes was done according to the criteria laid down by American Diabetic Association (1997).

A detailed clinical history was taken using a structured questionnaire. Data regarding the age, sex, religion, occupation, address, h/o smoking, alcoholism, dietary habit, diabetes, hypertension with duration and treatment were obtained and recorded. A complete clinical examination was done including the height and weight on light cloths of the subjects. All the diabetes patients were referred to ophthalmology department for evaluation of diabetic retinopathy by ophthalmological examination. The following examinations for themwere performed, a) Ocular examination in diffuse light b) Slit lamp examination c) Direct ophthalmoscopy, d) Indirect ophthalmoscopy and e)+ 90 diopter lens examination. Fundus photography was done by FF 450 plus fundus camera with digital imaging system. The retinopathy of the patients was graded as a) non-proliferative diabetic retinopathy (NPDR), b) proliferative diabetic retinopathy (PDR) and c) advanced proliferative diabetic retinopathy associated either with or without macular edema (ADR).

Hyperglycaemia was assessed by measuring $\mathrm{HbA1c} \%$. HbA1c $<7 \%$ was considered as the optimal control. Hypertension was diagnosed if SBP and DBP were found to be> 140 and $90 \mathrm{~mm}$ of $\mathrm{Hg}$ or the patient was on medication for hypertension. Cut off value for hypercholesterolemia was kept at $150 \mathrm{mg} \%$. BMI was calculated by the formula, weight in $\mathrm{kg}$ divided by height in $\mathrm{cm}$ squared. BMI $<25$ was considered as normal, above which the individual was considered as overweight. Urinary microalbuminuria was measured in the early morning first void urine sample by turbidometry method and $<20 \mathrm{mg} / \mathrm{l}$ was taken to be normal.

Statistical Analysis:The Statistical analysis was done using Statistical Package for Social Sciences (SPSS 16.0 version). Results were expressed as mean \pm standard deviation. T-test (for gender differences), One- way Analysis of Variance (for retinopathy categories), Multinomial logistic regression has been used along with common graphical tools like Scatter Plot and Box-Plot whenever appropriate. A p-value $<0.05$ was taken as statistically significant.

RESULTS: The study comprised one hundred type 2 diabetic patients with 61(61\%) females and39(39\%) males whose mean age was 57.78 \pm 9.4 ranging from 41 years to 83 years and the mean duration of diabetes was $8.41 \pm 5.30$ years (Table 2).The average age of female patients were marginally higher with $58.02 \pm 9.77$ years compared to $57.41 \pm 8.91$ of the male patients but the difference is not significant ( $\mathrm{p}>0.05$ ). The male patients had slightly longer duration of diabetes compared to the females ( $8.49 \pm 5.29$ vs. $8.36 \pm 5.36$ years, $p=0.908)$ as seen in Table 3.Nine $(9 \%)$ persons including a female were smokers and 5 persons (5\%), including 1 female, admitted frequent consumption of alcohol. The mean BMI of the patients under study was $23.55 \pm 2.84$ and it is observed that the females had a higher BMI than the males although not statistically significant (23.68 \pm 2.87 and $23.35 \pm 2.81, \mathrm{p}=0.571)$. Both systolic and diastolic blood pressures indicated higher average values for females than the males but the difference is not significant for both ( $>0.05)$.

The males in the study had higher average blood glucose values both fasting $(148.59 \pm 42.52$ vs. $145.11 \pm 41.83, \mathrm{p}=0.689)$ and postprandial $(240.85 \pm 56.15$ vs. $232.54 \pm 65.40, \mathrm{p}=0.501)$. The 
male patients also had higher HbA1C (7.95 \pm 1.11 vs. $7.78 \pm 1.23, \mathrm{p}=0.485)$ and MAU (42.95 \pm 24.17 vs. $41.21 \pm 26.04$ ) compared to the female patients which were however statistically not significant ( $p>0.05)$. Whereas female patients were found to have higher serum cholesterol levels $(198.90 \pm$ 34.66to $189.74 \pm 34.73$, $\mathrm{p}=0.202$ ) shown in Table 2 .

\begin{tabular}{|c|c|c|c|c|c|c|c|c|}
\hline \multicolumn{3}{|c|}{ Age (Years) } & 41 to50 & 51 to 60 & 61 to 70 & 71 to 80 & $81 \&$ above & Total \\
\hline \multirow{3}{*}{ Non-Retinopathy } & \multirow{2}{*}{ sex } & $\mathrm{F}$ & 18 & 16 & 1 & 0 & 0 & 35 \\
\hline & & M & 10 & 13 & 0 & 0 & 0 & 23 \\
\hline & \multicolumn{2}{|c|}{ Total } & 28 & 29 & 1 & $\mathbf{0}$ & $\mathbf{0}$ & 58 \\
\hline \multirow{3}{*}{ NPDR } & \multirow{2}{*}{ sex } & $\mathrm{F}$ & 0 & 3 & 3 & 2 & 0 & 8 \\
\hline & & $M$ & 0 & 2 & 3 & 2 & 0 & 7 \\
\hline & \multicolumn{2}{|c|}{ Total } & $\mathbf{0}$ & 5 & 6 & 4 & $\mathbf{0}$ & 15 \\
\hline \multirow{3}{*}{ PDR } & \multirow{2}{*}{$\operatorname{sex}$} & $\mathrm{F}$ & 0 & 4 & 7 & 1 & 0 & 12 \\
\hline & & $\mathrm{M}$ & 0 & 1 & 4 & 0 & 0 & 5 \\
\hline & \multicolumn{2}{|c|}{ Total } & $\mathbf{0}$ & 5 & 11 & 1 & $\mathbf{0}$ & 17 \\
\hline \multirow{3}{*}{ ADR } & \multirow{2}{*}{ sex } & $\mathrm{F}$ & 0 & 1 & 2 & 2 & 1 & 6 \\
\hline & & $M$ & 0 & 0 & 3 & 1 & 0 & 4 \\
\hline & \multicolumn{2}{|c|}{ Total } & $\mathbf{0}$ & 1 & 5 & 3 & 1 & 10 \\
\hline \multirow{3}{*}{ Total } & \multirow{2}{*}{ sex } & $\mathrm{F}$ & 18 & 24 & 13 & 5 & 1 & 61 \\
\hline & & $M$ & 10 & 16 & 10 & 3 & 0 & 39 \\
\hline & \multicolumn{2}{|c|}{ Total } & 28 & 40 & 23 & 8 & 1 & 100 \\
\hline & & & ge a & nder & le of $\mathrm{tl}$ & $\begin{array}{l}\text { Samples } \\
(\mathrm{N}=100)\end{array}$ & & \\
\hline
\end{tabular}

Source: Primary Data

\begin{tabular}{|c|c|c|c|c|c|}
\hline \multirow{2}{*}{ Parameters } & \multirow{2}{*}{ Mean } & \multirow{2}{*}{ T Score } & \multirow{2}{*}{$\begin{array}{l}\text { Standard } \\
\text { Deviation }\end{array}$} & \multicolumn{2}{|c|}{$95 \%$ CI of the Difference } \\
\cline { 5 - 6 } & & & Lower & Upper \\
\hline Age & 57.78 & $61.442^{* * *}$ & 9.40 & 55.91 & 59.65 \\
\hline Duration & 8.41 & $15.853^{* * *}$ & 5.30 & 7.36 & 9.46 \\
\hline BMI & 23.55 & $82.922^{* * *}$ & 2.84 & 22.49 & 23.61 \\
\hline BP sys & 126.00 & $85.636^{* * *}$ & 14.71 & 123.08 & 128.92 \\
\hline BP dia & 80.68 & $91.024^{* * *}$ & 8.86 & 78.92 & 82.44 \\
\hline Sugar F & 146.47 & $34.941^{* * *}$ & 41.92 & 138.15 & 154.78 \\
\hline Sugar PP & 235.78 & $38.153^{* * *}$ & 61.80 & 223.52 & 248.05 \\
\hline HBA1C & 7.85 & $66.415^{* * *}$ & 1.18 & 7.61 & 8.08 \\
\hline MAU & 41.89 & $16.613^{* * *}$ & 25.22 & 36.89 & 46.89 \\
\hline S Ch & 195.33 & $56.132^{* * *}$ & 34.80 & 188.43 & 202.23 \\
\hline \multicolumn{7}{r|}{ Table 2: Parameters of the patients with means, } \\
'T' Values and Confidence Intervals (n=100)
\end{tabular}

Source: Computed; Notes- All 'T' significant at.01 percent levels (D.F- 99) 
ORIGINAL ARTICLE

\begin{tabular}{|c|c|c|c|c|c|c|}
\hline \multirow{2}{*}{ Parameters } & \multicolumn{2}{|c|}{ Females } & \multicolumn{2}{|c|}{ Males } & \multirow{2}{*}{ ' $\mathrm{t}$ ' } & \multirow{2}{*}{$P$ value } \\
\hline & Mean & SD & Mean & SD & & \\
\hline AGE (Years) & 58.02 & 9.77 & 57.41 & 8.91 & -0.32 & .750 \\
\hline DURATION (Years) & 8.36 & 5.36 & 8.49 & 5.29 & 0.12 & .908 \\
\hline BMI & 23.68 & 2.87 & 23.35 & 2.81 & -0.57 & .571 \\
\hline BP SYS (mm Hg) & 127.54 & 14.58 & 123.59 & 14.78 & -1.31 & .194 \\
\hline BP DYS (mm Hg) & 81.67 & 9.16 & 79.13 & 8.26 & -1.44 & .154 \\
\hline GLUCOSE F (mg/dl) & 145.11 & 41.83 & 148.59 & 42.52 & 0.40 & .689 \\
\hline Glucose PP (mg/dl) & 232.54 & 65.40 & 240.85 & 56.15 & 0.68 & .501 \\
\hline HBA1C & 7.78 & 1.23 & 7.95 & 1.11 & 0.70 & .485 \\
\hline MAU (mg/l) & 41.21 & 26.04 & 42.95 & 24.17 & 0.34 & .735 \\
\hline $\mathrm{S} \mathrm{CH}(\mathrm{mg} / \mathrm{dl})$ & 198.90 & 34.66 & 189.74 & 34.73 & -1.29 & .202 \\
\hline
\end{tabular}

Source: Computed

Out of the 100 type 2 diabetics under study, 42(42\%) patients had diabetic retinopathy comprising 15(15\%) males and 27(27\%) females (Table 1). The prevalence of diabetic retinopathy was highest among the age group 61 to 70 years (52.38\%). It is observed that patients suffering from retinopathy were older in age $(66.57 \pm 6.45 \mathrm{vs} 51.41 \pm 5.05$. $\mathrm{p}<0.01)$ compared to the nonretinopathy patients with ADR patients being the oldest $(69.8 \pm 7.61)$, however the mean age difference between the three retinopathy groups were not statistically significant(p>0.05). Patients with retinopathy had longer duration of diabetes compared to the non-retinopathy population $(13.52 \pm 3.52$ vs. $4.08 \pm 2.60 . \mathrm{p}<0.01)$ ) and among the retinopathy population, patients with ADR group had the longest duration of diabetes (16.01 \pm 5.06$)$. In this study, age and duration of diabetes are strongly correlated with the prevalence of retinopathy (Fig 1).

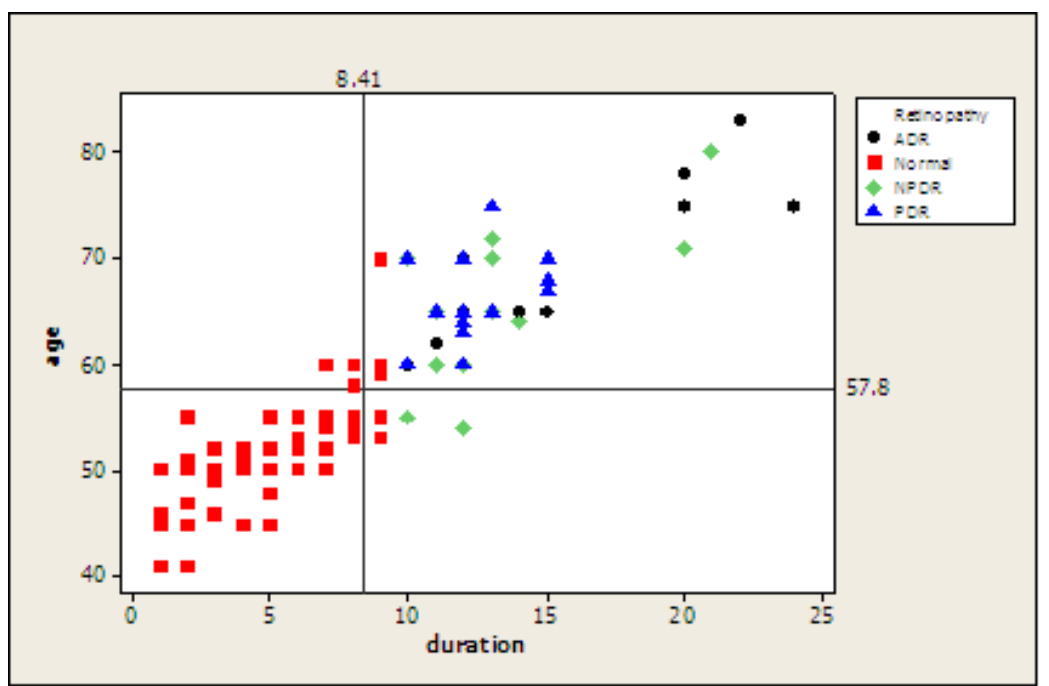

Fig. 1: Scatter Plot of Age and Duration

Source: Computed from Primary Data 
BMI, Systolic BP and Diastolic BP did not vary significantly among the retinopathy and noretinopathy patients ( $p>0.05$ ), while all other parameters like age, duration, glucose (f), glucose (PP), HBA1c, MAU and serum cholesterol were significantly different $(\mathrm{p}<0.05)$ (Table 4). The mean BMI and systolic BP were found higher in the ADR group ( $>>0.05)$, while the mean diastolic BP was higher in the non-retinopathy group ( $80.97 \pm 8.74$ vs. $80.29 \pm 9.12 ; p>0.05)$. It should be noted, here that, the differences in mean for these parameters were not statistically significant among the four categories. In the same way, statistically significant variation $(p>0.05)$ was not observed for the serum cholesterol level (Table 5) where the PDR group had the highest mean (206.76 \pm 27.99 ), while the non-retinopathy group had the least average level (188.52 \pm 38.95$)$.

\begin{tabular}{|l|c|c|c|c|c|c|}
\hline \multirow{2}{*}{\multicolumn{1}{|c|}{ Parameters }} & \multicolumn{2}{|c|}{ No Retinopathy } & \multicolumn{2}{c|}{ Retinopathy } & \multirow{2}{*}{ ' $\mathrm{t}$ ' } & \multirow{2}{*}{ P value } \\
\cline { 2 - 5 } & Mean & SD & Mean & SD & & \\
\hline AGE (Years) & 51.41 & 5.05 & 66.57 & 6.45 & -12.68 & 0.00 \\
\hline DURATION (Years) & 4.71 & 2.60 & 13.52 & 3.51 & -13.75 & 0.00 \\
\hline BMI & 23.26 & 2.94 & 23.96 & 2.67 & -1.24 & 0.22 \\
\hline BP SYS (mm Hg) & 124.8 & 13.9 & 127.6 & 15.7 & -0.92 & 0.36 \\
\hline BP DYS (mm Hg) & 80.97 & 8.74 & 80.29 & 9.12 & 0.37 & 0.71 \\
\hline GLUCOSE F (mg/dl) & 130.8 & 35.0 & 168.1 & 41.4 & -4.74 & 0.00 \\
\hline GLUCOSE PP (mg/dl) & 210.5 & 55.3 & 270.6 & 53.1 & -5.49 & 0.00 \\
\hline HBA1C & 7.36 & 1.01 & 8.51 & 1.08 & -5.41 & 0.00 \\
\hline MAU (mg/l) & 25.7 & 15.3 & 64.3 & 18.1 & -11.22 & 0.00 \\
\hline S CH (mg/dl) & 188.5 & 38.9 & 204.7 & 25.7 & -2.51 & 0.01 \\
\hline
\end{tabular}

Table 4: Mean \& SD of Samples along with ' $T$ ' test with retinopathy as factor $(\mathrm{n}=100$, retinopathy $=42 ;$ Non-retinopathy $=58)$

\section{Source: Computed}

The blood glucose levels for both fasting as well as postprandial were much higher in the retinopathy group compared to the non-retinopathy group which is statistically significant $(\mathrm{p}<0.01)$, while the average values of these two parameters within the three retinopathy classification did not vary much and the differences among ADR, PDR and NPDR were not statistically significant ( $p>0.05$ ). The blood glucose levels never the less were observed highest among the ADR group for both categories (Fig 2) Similar is the situation for HBA1C and MAU. The non-retinopathy group has the lowest mean $(\mathrm{HBA} 1 \mathrm{C}=7.36 \pm 1.01$; $\mathrm{MAU}=25.69 \pm 15.27$ ), which is significantly lower than the three retinopathy category ( $p<0.01$ ). For these two parameters also, we observe the average to be highest for the ADR group. Fig 3 shows that the non-retinopathy patients generally have lower levels of HbA1c and MAU, while both increases as the intensity of the disease increases. The regression equation for the categories show that the non-retinopathy line lies much below the other three categories. 


\section{ORIGINAL ARTICLE}

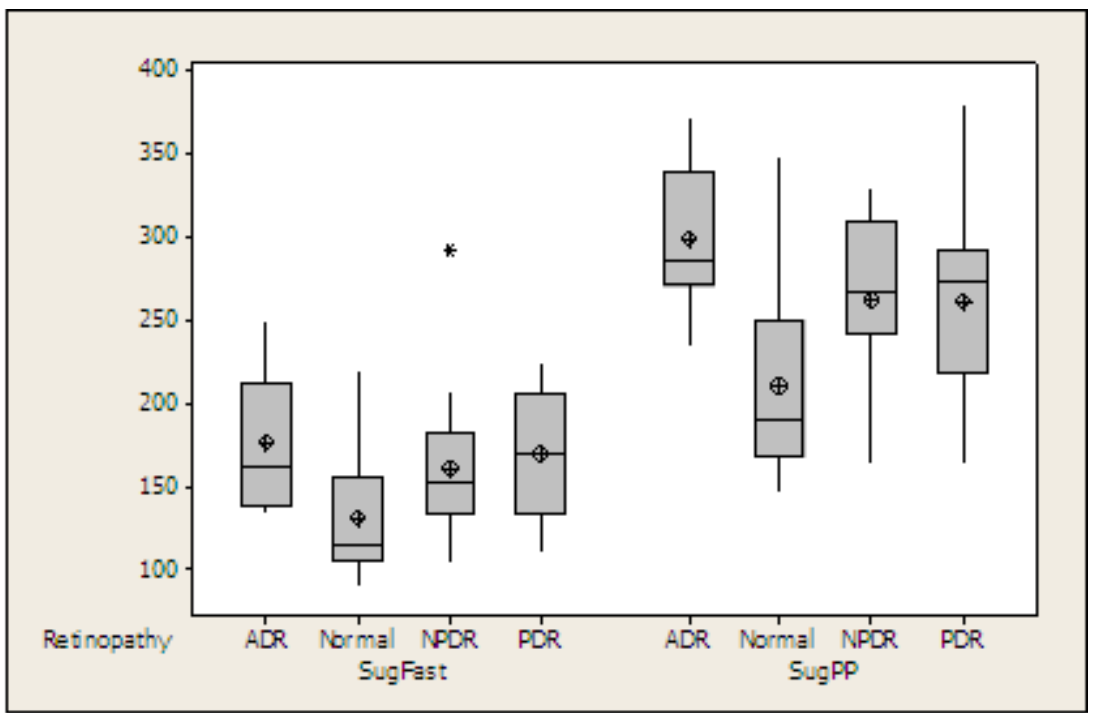

Fig. 2 Box Plot of Blood Sugar levels of Sample Groups

Source: Computed from Primary Data

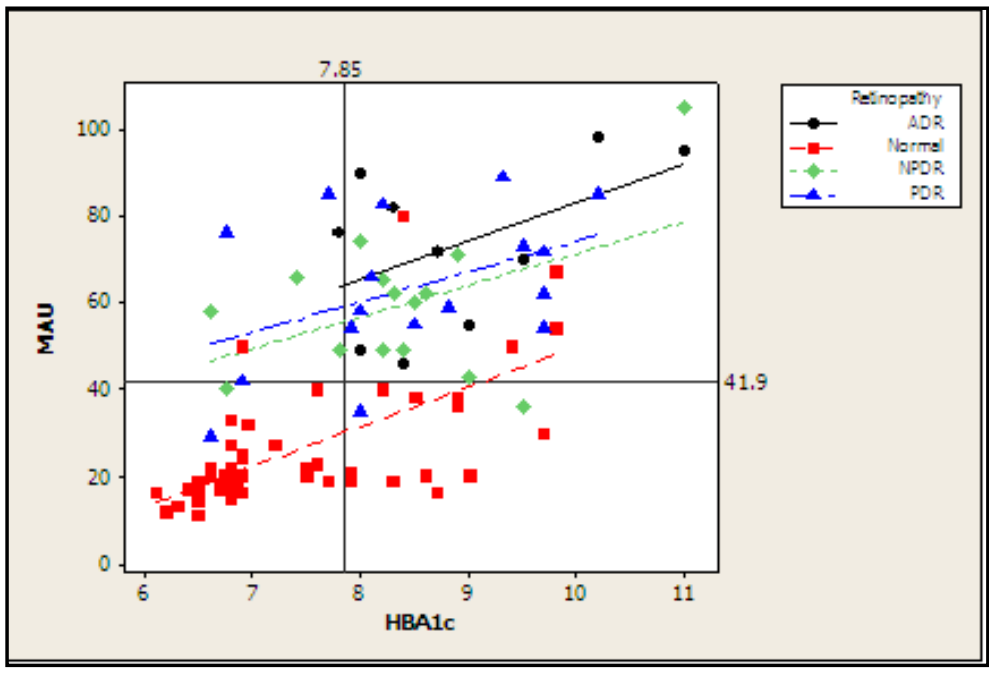

Fig. 3: Scatter Plot of HBA1C and MAU

Source: Computed from Primary Data

The table 5 supports our observations on the basis of the Table 4. The results of the Analysis of variance (test statistic, ' $F$ ') show significant variation $(p<0.01)$ among the four categories for age, duration, glucose (fasting), glucose (PP), HBA1C and MAU. A Sensitivity analysis was done incorporating the gender criterion as an added constraint for these variables and the new results (D.F: 7, 92) obtained corroborated the existing observation of significant differences even though the values of ' $F$ ' declined.

A multinomial logistic regression analysis undertaken with the four categories of retinopathy as dependent variable along with smoking, alcohol use, type of diet and gender as categorical variables while considering age, duration, blood pressure (systolic and diastolic), glucose (fasting 
and PP), HBA1C, MAU and serum cholesterol as co-variant. The model suggested a good fit, with Chisquare statistic $(=164.604)$ being highly significant and indicated that duration of the diabetes to be the most significant $(\mathrm{p}<0.001)$ contributor for retinopathy.

\begin{tabular}{|c|c|c|c|c|}
\hline Parameters & $\begin{array}{c}\text { No Retinopathy } \\
(\mathrm{n}=58)\end{array}$ & $\begin{array}{l}\text { NPDR } \\
(n=15)\end{array}$ & $\begin{array}{c}\text { PDR } \\
(n=17)\end{array}$ & $\begin{array}{c}\text { ADR } \\
(n=10)\end{array}$ \\
\hline AGE (Years) & $\begin{array}{c}51.41 \\
{[77.58]}\end{array}$ & $\begin{array}{c}65.87 \\
{[35.58]}\end{array}$ & $\begin{array}{c}65.29 \\
{[59.68]}\end{array}$ & $\begin{array}{c}69.8 \\
{[28.99]}\end{array}$ \\
\hline DURATION (Years) & $\begin{array}{c}4.71 \\
{[13.77]}\end{array}$ & $\begin{array}{c}13.00 \\
{[15.28]}\end{array}$ & $\begin{array}{l}12.53 \\
{[31.8]}\end{array}$ & $\begin{array}{c}16.01 \\
{[10.01]}\end{array}$ \\
\hline BMI & $\begin{array}{c}23.26 \\
{[60.29]}\end{array}$ & $\begin{array}{c}24.04 \\
{[39.76]}\end{array}$ & $\begin{array}{c}23.53 \\
{[31.15]}\end{array}$ & $\begin{array}{c}24.56 \\
{[31.98]}\end{array}$ \\
\hline BP SYS (mm Hg) & $\begin{array}{l}122.66 \\
{[46.65]}\end{array}$ & $\begin{array}{l}127.33 \\
{[35.56]}\end{array}$ & $\begin{array}{l}125.88 \\
{[30.57]}\end{array}$ & $\begin{array}{c}131 \\
{[23.96]}\end{array}$ \\
\hline BP DYS (mm Hg) & $\begin{array}{c}80.97 \\
{[70.55]}\end{array}$ & $\begin{array}{c}80.93 \\
{[52.30]}\end{array}$ & $\begin{array}{c}79.76 \\
{[28.74]}\end{array}$ & $\begin{array}{c}80.2 \\
{[26.84]}\end{array}$ \\
\hline GLUCOSE F (mg/dl) & $\begin{array}{l}130.79 \\
{[28.47]}\end{array}$ & $\begin{array}{l}161.33 \\
{[13.73]}\end{array}$ & $\begin{array}{l}169.26 \\
{[17.91]}\end{array}$ & $\begin{array}{c}176.3 \\
{[13.40]}\end{array}$ \\
\hline Glucose PP (mg/dl) & $\begin{array}{l}210.54 \\
{[28.98]}\end{array}$ & $\begin{array}{c}262.3 \\
{[20.43]}\end{array}$ & $\begin{array}{l}261.67 \\
{[18.97]}\end{array}$ & $\begin{array}{c}298.4 \\
{[20.49]}\end{array}$ \\
\hline HBA1C & $\begin{array}{c}7.36 \\
{[55.62]}\end{array}$ & $\begin{array}{c}8.34 \\
{[30.08]}\end{array}$ & $\begin{array}{c}8.44 \\
{[31.24]}\end{array}$ & $\begin{array}{c}8.89 \\
{[26.74]}\end{array}$ \\
\hline $\begin{array}{c}\text { MAU } \\
(\mathrm{mg} / \mathrm{l})\end{array}$ & $\begin{array}{c}25.69 \\
{[12.81]}\end{array}$ & $\begin{array}{c}59.27 \\
{[13.52]}\end{array}$ & $\begin{array}{l}63.35 \\
{[14.7]}\end{array}$ & $\begin{array}{c}73.3 \\
{[12.44]}\end{array}$ \\
\hline $\begin{array}{c}\mathrm{S} \mathrm{CH} \\
(\mathrm{mg} / \mathrm{dl})\end{array}$ & $\begin{array}{l}188.52 \\
{[36.89]}\end{array}$ & $\begin{array}{l}204.87 \\
{[36.92]}\end{array}$ & $\begin{array}{l}206.76 \\
{[30.46]}\end{array}$ & $\begin{array}{c}201.1 \\
{[21.59]}\end{array}$ \\
\hline
\end{tabular}

Notes- Figures in parentheses are the 'T' values and All ' $T$ ' significant at.01 percent levels

\begin{tabular}{|c|c|c|c|c|c|c|}
\hline & & Sum of Squares & Df & Mean Square & $\mathrm{F}$ & P value \\
\hline \multirow{3}{*}{ age * } & Between Groups & 5736.228 & 3 & 1912.076 & 60.803 & .000 \\
\hline & Within Groups & 3018.932 & 96 & 31.447 & & \\
\hline & Total & 8755.160 & 99 & & & \\
\hline \multirow{3}{*}{ Duration * } & Between Groups & 1975.937 & 3 & 658.646 & 78.037 & .000 \\
\hline & Within Groups & 810.253 & 96 & 8.440 & & \\
\hline & Total & 2786.190 & 99 & & & \\
\hline \multirow{3}{*}{ Glucose F* } & Between Groups & 35299.618 & 3 & 11766.539 & 8.147 & .000 \\
\hline & Within Groups & 138658.009 & 96 & 1444.354 & & \\
\hline & Total & 173957.628 & 99 & & & \\
\hline \multirow{3}{*}{ Glucose PP * } & Between Groups & 98098.037 & 3 & 32699.346 & 11.211 & .000 \\
\hline & Within Groups & 280000.218 & 96 & 2916.669 & & \\
\hline & Total & 378098.254 & 99 & & & \\
\hline
\end{tabular}


ORIGINAL ARTICLE

\begin{tabular}{|c|l|c|c|c|c|c|}
\hline \multirow{3}{*}{ HBA1C * } & Between Groups & 34.274 & 3 & 11.425 & 10.557 & .000 \\
\cline { 2 - 7 } & Within Groups & 103.889 & 96 & 1.082 & & \\
\cline { 2 - 7 } & Total & 138.163 & 99 & & & \\
\hline \multirow{3}{*}{ MAU * } & Between Groups & 37448.461 & 3 & 12482.820 & 46.995 & .000 \\
\cline { 2 - 7 } & Within Groups & 25499.329 & 96 & 265.618 & & \\
\cline { 2 - 7 } & Total & 62947.790 & 99 & & & \\
\hline \multirow{3}{*}{ BP Sys } & Between Groups & 6611.935 & 3 & 2203.978 & 1.868 & .140 \\
\cline { 2 - 8 } & Within Groups & 113270.175 & 96 & 1179.898 & & \\
\cline { 2 - 8 } & Total & 119882.110 & 99 & & & \\
\hline & Between Groups & 356.626 & 3 & 118.875 & 0.541 & .655 \\
\cline { 2 - 8 } & Within Groups & 21075.374 & 96 & 219.535 & & \\
\hline \multirow{3}{*}{ BP Dia } & Total & 21432.00 & 99 & & & \\
\cline { 2 - 8 } & Within Groups & 7755.523 & 96 & 80.787 & & \\
\cline { 2 - 8 } & Total & 7777.760 & 99 & & & \\
\hline \multirow{3}{*}{ BMI } & Between Groups & 18.739 & 3 & 6.246 & 0.772 & .513 \\
\cline { 2 - 7 } & Within Groups & 776.933 & 96 & 8.093 & & \\
\cline { 2 - 7 } & Total & 795.672 & 99 & & & \\
\hline
\end{tabular}

Source: Computed

DISCUSSION: In this study we have observed a relatively higher prevalence of retinopathy (42\%) with female predominance ( $27 \%$ vs. $15 \%)$, which agrees with the findings of otherstudies. ${ }^{2,4}$ ${ }^{8}$ However a number of studies showed a lower prevalence of diabetic retinopathy. ${ }^{1,3,9-15}$ Factors like unawareness of diabetes among the population, lack of facilities to check regularly retinopathy and other complications could have attributed to the higher prevalence of diabetic retinopathy in our study.

In our study, among the 3 categories of retinopathy PDR was found to be highest (17\%), followed by NPDR (15\%) and ADR (10\%). This finding agrees with the findings of Lertkoonalak et al 12 who reported higher prevalence of PDR (95\%) than NPDR (7.6\%) in their study. Verna and his colleagues 16 also reported more of severe PDR (6.1\%) compared to NPDR (4.4\%) and they observed macular edema in $(10.1 \%)$ of their patients of diabetic retinopathy. However other workers (Chethakul et al ${ }^{4}$, Al Amer et al 2, Wover et al5, and Mahar et al 16 observed NPDR more prevalent than PDR in their respective studies.

The average age of the sample respondent is 57.78 years and the average duration of diabetes is 8.41 years in our study which agrees with the studies conducted by Al Amer et al ${ }^{2}$ who found mean age was 57.8 years and duration of DM 9.6years in their study and also by Al- Sammari et $\mathrm{al}^{3}$ where mean age was $54.28 \pm 8.7$ years and duration of diabetes was ( $13.2 \pm 5.8$ years).

Age, duration of diabetes, blood glucose both fasting and postprandial, HbA1c and urinary microalbuminuria were found to be associated with diabetic retinopathy which are statistically significant and out of these, duration of diabetes was the most significant contributor for the retinopathy. The same observation was also seen in a number of studies conducted in different parts of the world. ${ }^{2-4,7,10,12-15,17}$ The average duration of diabetes, was 8.41 years and that of different 


\section{ORIGINAL ARTICLE}

categories of individual like non - retinopathy, NDPR, PDR and ADR was 4.71, 13.0, 12.53 and 16.01 years respectively. In a study Kleinet al 18 also mentioned that the prevalence of diabetic retinopathy varied from $17 \%$ to $97.5 \%$ in persons with diabetes for $<5$ years and $>15$ years or more years respectively.

In our study age also was found to be statistically significant factor in occurrence of diabetic retinopathy. Mean age of the individuals was 57.78 years. Non-retinopathy group had the average age only 51.41 years and different retinopathy groups NPDR, PDR, and ADR was 65.87, 65.29 and 69.8 years respectively. The maximum occurrence of the retinopathy was in the age group of 61.70 years (22\%) and all the patients in groups of 71 to.80 years and 81 years and above had retinopathy of any categories. Chetthakul $\mathrm{T}$ et al ${ }^{4}$, Klein $\mathrm{R}$ et al ${ }^{18} \&$ Maskari FA ${ }^{13}$ also mentioned that increasing age is a risk factor in occurrence of diabetic retinopathy.

HbA1c which is considered the gold standard for the glycemic control of the diabetic patients found to be a very important risk factor for diabetic retinopathy as mentioned in different studies worldwide.2, 3, 4, 7, 10,13,14,15,17 HbA1c is found to be statistically significant risk factor for DR in our study also. HbA1c in non - retinopathy, NPDR, PDR, and ADR group were 7.36, 8.44, and 8.89 respectively. From this data it is quite evident that the higher HbA1c i.e. poor glycemic control the more the risk of diabetic retinopathy. Blood glucose level as measured by blood glucose (Fasting) and (PP) also found to be statistically significant in occurrence of DR. Mean blood glucose (F) \& (pp) for the non - retinopathy group were 130.29 and $210.54 \mathrm{mg} \%$ respectively. Whereas blood glucose (F) \&(PP) levels in NPDR, PDR, and ADR groups were higher, 161.33 \& $262.3 \mathrm{mg} \%, 169.26$ and $261.67 \mathrm{mg} \%$ and $176.3 \& 298.4 \mathrm{mg} \%$ respectively. Chetthakulet al ${ }^{4}$ also observed a statistically significant higher blood glucose level in DRin their study.

Urinary microalbuminuria (MAU) was also observed to be a statistically significant risk factor for diabetic retinopathy in our study which was also observedin a number of studies. ${ }^{3,5,7,12,17}$ The mean value of MAU in non - retinopathy, NPDR, PDR and ADR are 25.69, 59.27, 63.35 and 73.3, makes it quite evident that more the MAU value more the severity of retinopathy.

Though systolic blood pressure (SBP) was found to be a significant risk factor in some of the studies 4,10,12,18 and diastolic blood pressure (DBP) and mean arterial pressure in the studies conducted by Beket al ${ }^{10}$ and Park et al ${ }^{15}$, our study failed to establish the relationship between the SBP, DBP or mean arterial pressure with diabetic retinopathy. It is most probably due to a better control of blood pressure as evidenced by the normal mean SBP and DBP in the individuals in our study. Mohanet al ${ }^{14}$ also could not establish hypertension as a risk factor for DR in their study. Serum cholesterol could not be established as a risk factor in our study which is a similar finding in the study conducted by Jostet al 7 , though Mohanet al ${ }^{14}$ and Park CY ${ }^{15}$ found hypercholesterolemia as a risk factor for DR.

In our study females are found to have retinopathy more in number, but failed to establish any statistical significance. Likewise smoking and alcohol intake also did not have any significant correlation with diabetic retinopathy. It may be due to a very few patients with smoking and alcohol intake in the study.

CONCLUSION: The prevalence of DR in diabetes mellitus patients of Tripura is relatively high. Also there is high prevalence of PDR and ADR. Age, duration of diabetes, blood glucose both fasting and postprandial, HbA1c and urinary microalbuminuria were found to be significantly associated with 


\section{ORIGINAL ARTICLE}

diabetic retinopathy and duration of diabetes was the most significant contributor for the retinopathy.The cause of severe type of retinopathy may be attributed to poor glycemic control for a longer duration which may be due to lack of awareness among the diabetic patients in our place. It may be avoided by regular and periodical retinal check up in the part of the diabetic patients.

\section{REFERENCES:}

1. Abdollahi A, Malekmadani M.H, Mansoori MR, Bostak A, Abbaszadeh MR and Mirsahi A. Prevalence of Diabetic Retinopathy in newly diagnosed type-II Diabetes Mellitus ; ActaMedicaIranica; 2006: 44(6): 415- 419.

2. Al-Amer RM, Khader Y, Malas S, Abu-Yashi N, Ai- Bdour M, Ajloumi K. Prevalence and risk factors of Diabetic Retinopathy among Jordanian patients with type -2 Diabetes; Digital Journal of Ophthalmology; 2008: 14(2).

3. Al-Shammari FKH, Al-Meraghi 0, Nasif A, Al-Otaibi S. The prevalence of Diabetic Retinopathy and associated risk factors in type-2 Diabetes Mellitus in Al- Naeemarea (Kuwait). Middle East Journal of Family Medicine; May2005: 3(2).

4. Chetthakul T, DeerochanawongCh, Suwanwalaikom S, Kosachunhanun N et al. Thailand Diabetes Register Project: Prevalence of Diabetic Retinopathy andassociated factors in type-2 Diabetes Mellitus ; J Med Assoc Thai 2006: 89(1): 27- 36.

5. Glover SJ, Burgess PI, Cohen DB, Harding SP, Hofland HW, Zijlstra EE, Allains TJ. Prevalence of diabetic retinopathy, cataract and visual impairment in patients with diabetes in Sub-Saharan Africa; Br. J Ophthalmol: April 2011.

6. Hein KS, Seng CK. Prevalence of Diabetic Retinopathy in a primary care setting using Digital Retinal imaging technology ; Malaysian Family Physicians; 2006 :1(1): 19-22.

7. Jost BS, Hilgemberg E, Rodrigues EB, Daniotti AF, Bonamigo EL. Prevalence of diabetic retinopathy in patients affected by type-2 Diabetes Mellitus in the city of Luzerna -SCJ ; Arq Bras Oftalmol; 2010 Jun: 73(3): 259-65.

8. Verna R, Torres M, Pna F, Kleeis R, Azen SP \& Los Angeles Latino eye Study groups. Prevalence of diabetic retinopathy in adult Latins: The Los Angeles Latino Eye Study. Ophthalmology 2004, 41(7), 1298-1306.

9. Al-Zuabi H, Al-Tammar Y, Al-Moataz R, Al-Sabti K, Wani VB, Hamam F, Mohammad H, AlSuwayan MH. Retinopathy in newly diagnosed type-2 Diabetes Mellitus; Med PrincPract; 2005: 14: 293- 296.

10. Bek T, Anderson HL, Hansen AB, Johnsen KB, Sandback A, Lauritzen T. The prevalence of Diabetic retinopathy in patients with screen detected type-2 Diabetes in Denmark: The ADDITION study; ActaOphthalmologica; May 2009: 87(3): 270-274.

11. Ellis JD, Zvandasara T, Leese G, McAlpine R, Macewen CJ, Banies PS, Crombie I, Morris AD. Clues to duration of undiagnosed disease from retinopathy and maculopathy at diagnosis in type 2 diabetes: across sectional study; Br J Ophthalmol : Sep 2011: 95(9): 1229-1233. 


\section{ORIGINAL ARTICLE}

12. Lertkoonalak R, Chetthakul T, Tantiwong A, Kantisophon L. Prevalence of Diabetic Retinopathy and associated factors in type 2 Diabetes Mellitus in MaharatNakhonRatchasima hospital. Maharat Nakhon Ratchasima hospital medical bulletin ; 2008: 2(3).

13. Maskari FA and Sadig ME. Prevalence of Diabetic Retinopathy in the United Arab Emirates: a cross sectional survey. BMC Ophthalmology 2007:7(11).

14. Mohan R, Sundaram PK, Balaji A, Raj D, Rajendra P and Viswanathan Mohan. Prevalence of Diabetic Retinopathy in Urban India: The Chennai Urban Rural epidemiology study (CURES) Eye Study I.

15. Park CY, Park SE, Bac JC, Kim WJ, Park SW, Ha MM, Sons SJ. Prevalence of and risk factor for diabetic retinopathy in Korean with type II diabetes: baseline characteristics of Seol Metropolitan City- diabetes prevention programme (SMC - DPP) Participants.

16. Mahar PS, Awan MZ, Manzar N, Menon MS. Prevalence of Type 2 Diabetes Mellitus and Diabetic Retinopathy: The Gaddap Study. Journal of the College of Physicians and Surgeon, Pakistan, 2010. 20 (8): 528 - 532.

17. Ling CAIX, Fang W, Linong JI. Risk factors of diabetic retinopathy in type 2 diabetic patients; Clin Med J; 119(10): 822-826.

18. Klein R, Klein BEK, Moss SE, Davis MD, DeMets DL. The Wisconsin Epidemiologic study of Diabetic Retinopathy. II. Prevalence and risk of Diabetic Retinopathy when age at diagnosis is less than 30 years; Arch ophthalmol;1984: 102(4): 520-526.

\section{AUTHORS:}

1. ArindamDatta

2. Amar KantiChakma

3. Debasis Datta

\section{PARTICULARS OF CONTRIBUTORS:}

1. Associate Professor, Department of Medicine, Tripura Medical College \&Dr. BRAM Teaching Hospital, Hapania, Agartala.

2. Associate Professor, Department of Ophthalmology, Tripura Medical College, Hapania, Agartala.

3. Professor \& HOD, Department of Ophthalmology, Tripura Medical College, Hapania, Agartala.

\section{NAME ADDRESS EMAIL ID OF THE CORRESPONDING AUTHOR:}

Dr. Amar Kanti Chakma, Department of Ophthalmology, Tripura Medical College \& DR. BRM Teaching Hospital, Hapania, Agartala - 14.

Email-amarkanti@yahoo.com

Date of Submission: 28/11/2013. Date of Peer Review: 30/11/2013. Date of Acceptance: 05/12/2013. Date of Publishing: 02/01/2014 